\title{
On Prophecy, Dreams and Human Imagination
}

Synesius, De insomniis

Introduction, Text, Translation and Interpretative Essays by Donald A. Russell, Ursula Bittrich, Börje Bydén, Sebastian Gertz, Heinz-Günther Nesselrath, Anne Sheppard, Ilinca Tanaseanu-Döbler. Ed. by Donald A. Russell and Heinz-Günther Nesselrath

[Über Prophezeiungen, Träume und die menschliche Vorstellungskraft. Synesios, De insomniis .]

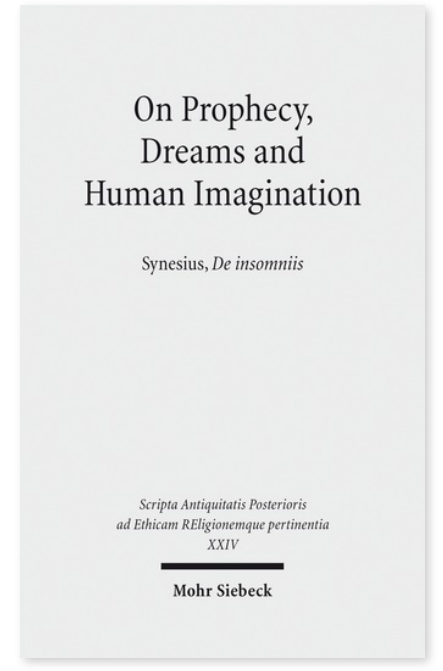

2014. X, 208 Seiten. SAPERE XXIV

ISBN 978-3-16-156431-4

DOI 10.1628/978-3-16-156431-4

eBook PDF

ISBN 978-3-16-152419-6

Leinen $59,00 €$

\section{Veröffentlicht auf Englisch.}

Synesios' Essay De insomniis (»Über Träume«) - bald nach 400 n. Chr. von jemandem geschrieben, der nicht nur ein hochgebildeter griechischer Intellektueller war, sondern in den letzten Jahren seines Lebens auch christlicher Bischof von Ptolemais (Cyrenaika) - fragt nach den Mitteln und Wegen, über die der Mensch in Schlaf und Traum mit höheren Sphären Kontakt aufnehmen kann, und tut dies vor dem Hintergrund einer erkennbar neuplatonischen Seelen- und Heilsvorstellung. Synesius' Gedanken sind damit ein wichtiger Beitrag der späteren Antike zu Themen - dem Platz des Menschen im Universum und seiner möglichen Beziehung zu höheren Mächten - die nicht nur damals, sondern auch in der Gegenwart für philosophisch und religiös interessierte Menschen von Bedeutung sind. Neben Einleitung und Übersetzung mit Anmerkungen erschließen mehrere Essays die Schrift aus verschiedenen Fachperspektiven.

Donald A. Russell Born 1920; professor of classical literature at the Faculty of Classics, University of Oxford; emeritus fellow and former tutor in classics at St John's College, Oxford.

Heinz-Günther Nesselrath Geboren 1957; 1976-81 Studium der Klassischen Philologie und der Alten Geschichte an der Universität zu Köln; 1981 Promotion; 1987 Habilitation; 1992-2001 vollamtlicher Professor für Klass. Philologie an der Universität Bern; seit 2001 Universitätsprofessor für Klass. Philologie an der Georg-August-Universität Göttingen.
Jetzt bestellen:

https://mohrsiebeck.com/buch/on-prophecy-dreams-and-human-imagination-9783161564314?no_cache=1 order@mohrsiebeck.com

Telefon: +49 (0)7071-923-17

Telefax: $+49(0) 7071-51104$ 